\title{
ARTIKEL AUDIT KEAMANAN SISTEM INFORMASI \\ PADA KANTOR PEMERINTAH KOTA BANDAR LAMPUNG MENGGUNAKAN COBIT 5
}

\author{
Firdia Riani \\ 155100033 \\ Universitas Mitra Indonesia, Sistem Informasi \\ Firdiariani.students@umitra.ac.id
}

\begin{abstract}
ABSTRAK
Sebagai institusi pemerintahan yang sudah memanfaatkan teknologi informasi dan komunikasi, Pemerintah Kota Bandar Lampung mempunyai Peraturan Walikota Bandar Lampung Nomor 78 Tahun 2007 tentang Standar Operasional dan Prosedur Manajemen Pengamanan Sistem Informasi dan Komunikasi pada Pemerintahan Kota Bandar Lampung. Selama ini Pemerintah Kota Bandar Lampung belum pernah melaksanakan audit terhadap Keamanan Sistem Informasi. Penelitian ini akan melakukan audit keamanan sistem informasi pada Pemerintah Kota Bandar Lampung menggunakan COBIT 5 untuk Keamanan Informasi. Pemilihan proses diukur melalui pemetaan tujuan. kaskade menghasilkan lima proses dalam COBIT 5. Responden berjumlah sembilan orang pegawai yang berperan dan bertanggung jawab langsung terhadap pengelolaan sistem informasi. Hasil pengukuran nilai kapasilitas keamanan SI di Pemerintah Kota Bandar Lampung dari lima proses, semua proses berada pada tingkat kapabilitas Performed Process. Tujuan kaskade COBIT 5 adalah mekanisme untuk menerjemahkan kebutuhan para pemangku kepentingan menjadi tujuanperusahaan yang spesifik, bisa dilaksanakan dan disesuaikan, tujuan terkait TI dan tujuan enabler. Memperkenankan penetapan tujuan yang spesifik pada setiap tingkatan dan di setiap wilayah dari perusahaan dalam mendukung tujuan keseluruhan dan kebutuhan para pemangku kepentingan.
\end{abstract}

Kata Kunci: Audit Keamanan, Kantor Pemerintahan, Menggunakan COBIT 5 


\section{A. PENDAhULUAN}

Audit Sistem Informasi adalah proses pengumpulan dan penilaian bukti-bukti untuk menentukan apakah sistem komputer dapat mengamankan aset, memelihara intergritas data, dapat mendorong pencapaian tujuan secara efektif dan menggunakan sumberdaya secara efisien. Ron Weber $(1999,10)$

Sebagai institusi pemerintahan yang sudah memanfaatkan teknologi informasi dan komunikasi, pemerintahan kota Bandar Lampung, menyadari perlunya adanya standar operasional dan prosedur manajemen pengaman sistem informasi dan telekomunikasi dilingkungan pemerintahan Kota Bandar Lampung. Prosedur manajemen pengamanan sistem informasi pemerintahan kota Bandar Lampung ditetapkan untuk dijadikan pedoman dan acuan dalam mengelola dan menggunakan perangkat serta sistem yang terkait dengan

teknologi informasi dan komunikasi dilingkungan Pemerintahan Kota Bandar Lampung. Keamanan sistem Informasi pada era teknologi Informasi dan komunikasi ini sangat penting, sistem informasi telah meningkatkan sebagai ancaman menjadi lebih luas dan rumit, maka dari itu keamanan informasi telah menjadi masalah yang mendasar untuk bisnis, organiasai dan pemerintahan. Peraturan Walikota Bandar Lampung tentang standar Operasional dan prosedur
Manajemen pengamanan sistem infromasi dan komunikasi pada pemerintah Kota Bandar Lampung. Selama kurun waktu ini pemerintahan kota Bandar Lampung belum pernah melaksanakan audit sistem terhadap keamanan Sistem informasi melalui audit keamanan pada pemerintahan Kota Bandar Lampung. Di harapkan mampu mengetahui keamanan tingkat kapabilitas keamanan sistem informasi.

Tingkat keamanan sistem informasi sangatlah penting juga bagi masyarakat agar supaya tingkat keamanan lebih efektif. Pemerintahan Kota Bandar Lampung sudah memanfaatkan Teknologi Informasi dan Komunikasi melalui pengembangan aplikasi-aplikasi yang mendukung pelayanan masyarakat.

\section{B. TINJAUAN PUSTAKA}

Banyak penelitian mengenai COBIT 5 yang membuktikan bahwa COBIT 5 merupakan kerangka kerja untuk Audit Sistem Informasi dan mampu menyediakan tata kelola keamanan informasi yang menyeluruh. Bahkan tujuan dari dalam COBIT 5 terkait teknologi informasi tentang keamanan dan salah satu produk dari COBIT 5 yang khusus fokus pada keamanan informasi yaitu COBIT 5 for Information Security. Menjadikan COBIT 5 sebagai metode yang tepat untuk melakukan audit keamanan Sistem Informasi bagi Pemerintah Kota Bandar Lampung. (Speremic, 2011:5) 
Pada praktiknya, keamanan Sistem informasi tidak hanya menyangkut aspek teknis saja melainkan juga menyangkut aspek nonteknis. Kelebihan COBIT untuk metrik, tolak ukur, dan melaksankan audit serta menyediakan tata kelola dan manajemen menyeluruh yang mampu mencangkup aspek teknis dan aspek nonteknis yang melandasi pemilihan COBIT 5 untuk audit keamanan sistem informasi.

(Sahibuddin, 2008:5)

\section{STUDI KASUS}

Sistem Pengamanan kota Bandar Lampung menggunakan COBIT 5 yang bertujuan untuk mengatasi masalah keamanan sistem informasi dengan menggunakan COBIT 5 untuk terjaminnya keamanan informasi sebagai kerangka kerja untuk melakukan audit keamanan Sistem Informasi. Sisi positif menggunakan COBIT 5 sebagai kerangka kerja tata kelola Keamanan Informasi adalah bahwa keamanan informasi 'terpadu' ke dalam kerangka tata kelola TI yang lebih besar atau lebih luas, yang disediakan oleh tiga puluh tujuh proses COBIT 5. Kemudahan COBIT 5 untuk selaras dengan kerangka kerja audit dan standar keamanan lainnya seperti Bill 198, COSO, ISO/IEC 27001, ISO/IEC 27002, ISO/IEC ISO / IEC 12207. COBIT berisi tentang tata kelola TI dan mengacu pada masalah-masalah lainnya, salah satu diantaranya memiliki komponen substansial yang terkait dengan Keamanan Informasi. Apabila seluruh proses dalam COBIT dikelola dengan baik, maka akan menghasilkan tata kelola TI yang tepat.

\section{DISKUSI}

Mengenai studi kasus keamanan Kota Bandar Lampung, maka akan dibahas mengenai tingkat penetapan keamanan pada pemerintahan Kota Bandar Lampung.

1. Identifikasi Responden,

Dalam Rencana Induk $e$ government disebutkan bahwa penanggung jawab penyelenggaraan pengembangan e-government Pemerintah Daerah adalah instansi yang membidangi pengembangan Teknologi teknologi informasi di Pemerintah Kota Bandar Lampung, instansi yang membidangi pengembangan teknologi informasi adalah Bagian Teknologi Informasi dan Telematika (TIT) Sekertariat daerah Kota Bandar Lampung. Jadi yang akan menjadi responden sasaran penelitian adalah para pegawai di Bagian Teknologi Informasi dan Telematika Sekertariat daerah Kota Bandar Lampung yang tugas pokok dan fungsinya menangani dan bertanggung jawab terhadap sistem informasi.

2. Penetapan Level yang dicapai Pemerintahan Kota Bandar Lampung pada bagian teknologi informasi dan Telematika Sekretariat daerah belum menggunakan COBIT 5 untuk keamanan informasi sebagai kerangka kerja penyususun 


\begin{abstract}
rencana strategis Teknologi Informasi, sehingga pada target yang ingin dicapai pada penyusunan rencana strategi teknologi informasi di pemerintahan kota Bandar Lampung tidak bisa untuk menentukan target kapabilitas proses yang ingin dicapai dalam COBIT 5 untuk keamanan informasi. Setelah Kepala Bagian TIT berdiskusi dengan Kepala Sub Bagian Aplikasi TIT dan Kepala Sub Bagian Perangkat Keras dan Jaringan TI, ketiganya sepakat untuk menetapkan target kapabilitas proses yang ingin dicapai dalam jangka pendek adalah level 3. Tapi dalam jangka panjangnya, Kepala Bagian TIT, Kepala Sub Bagian Aplikasi TIT dan Kepala Sub Bagian Perangkat Keras dan Jaringan TI menentukan level 5 sebagai target kapabilitas yang ingin dicapai.
\end{abstract}

3. Hasil Kapabilitas Keamanan Sistem Infomasi

Hasil nilai kapabilitas keamanan SI berada pada kisaran $\mathrm{P}$ (Partially Achieved) $15-50 \%$ dan ada satu proses yang berhasil mencapai kisaran L (Largely Achieved) 50-85\%.

a. Proses EDM03 Mengelola Optimasi Risiko memperoleh predikat P (Partially Achieved) karena memperoleh nilai 23,21\%.

b. Proses APO12 Mengelola Risiko memperoleh predikat $\mathrm{P}$ (Partially Achieved) karena memperoleh nilai 24,59\%.

c. Proses AOP13 Mengolah keamanan
predikat P $\begin{gathered}\text { memperoleh } \\ \text { Partially }\end{gathered}$ Achieved) karena memperoleh nilai $22,28 \%$.

d. Proses BAI06 mengelola Mengelola Keamanan memperoleh predikat $\mathrm{P}$ (Partially Achieved) karena memperoleh nilai $18,61 \%$.

e. Proses DSS05 Mengelola Layanan Keamanan memperoleh predikat L (Largely Achieved) karena memperoleh nilai $54,1 \%$.

Hasil pengukuran kapabilitas keamanan SI menunjukkan bahwa dari kelima proses yang diukur tidak ada yang mampu mencapai level yang ditargetkan, yaitu level 3. Bahkan dari kelima proses itu hanya bisa mencapai level 1 .

a. Proses EDM03 Mengelola Optimasi Risiko mencapai level 1,23.

b. Proses APO12 Mengelola Risiko mencapai level 1,24.

c. Proses APO13 Mengelola Keamanan mencapai level 1,22.

d. Proses BAI06 Mengelola Keamanan mencapai level 1,18 .

e. Proses DSS05 Mengelola Layanan Keamanan mencapai level 1,54.

\section{E. KESIMPULAN}

Berdasarkan kapabilitas keamanan Sistem Informasi Pemerintahan Kota Bandar Lampung, dapat disimpulkan, yaitu:

Hasil penilaian tingkat kapabilitas keamanan SI tidak dapat mencapai level yang ditargetkan dalam jangka pendek yaitu level 3. Hal ini diakibatkan beberapa hal sebagai berikut: 
1) Pemerintah Kota Bandar Lampung memang belum menerapkan COBIT 5 untuk Keamanan Informasi sebagai kerangka kerja untuk keamanan SI di Pemerintah Kota Bandar Lampung.

2) SOP (Standar Operasional Prosedur) mengenai kebijakan terkait keamanan SI di Pemerintah Kota Bandar Lampung. Sehingga meski sudah melakukan beberapa prosedur terkait keamanan SI, tidak mampu memperoleh nilai maksimal dalam penilaian tingkat kapabilitas keamanan SI.

3) Skala prioritas seringkali menyebabkan beberapa kegiatan terkait keamanan SI tidak dilakukan atau cenderung di abaikan oleh petugas keamanan.

Untuk meningkatkan tingkat kapabilitas keamanan SI agar mencapai level yang ditargetkan, Bagian TIT Sekretariat daerah Kota Bandar Lampung harus melakukan serangkaian praktik dasar perbaikan proses dan menghasilkan serangkaian produk kerja pada level 1 kinerja proses (performed process). Dilanjutkan dengan melakukan serangkaian praktik generik dan produk kerja generik pada level 2 proses dikelola (managed process).

\section{F. REFERENSI}

[1] PUTRA, Arie Setya; FEBRIANI, Ochi Marshella. Knowledge Management Online Application in
PDAM Lampung Province. In: Prosiding International conference on Information Technology and Business (ICITB). 2018. P. 181-187.

[2] FEBRIANI, Ochi Marshella; PUTRA, Arie Setya. Sistem Informasi Monitoring Inventori Barang Pada Balai Riset Standardisasi Industri Bandar Lampung. Jurnal Informatika, 2014, 13.1: 90-98

[3] Putra, A. S. (2018, July 9). 2018 Artikel Struktur Data, Audit dan Jaringan Komputer. Retrieved from osf.io/3uq8w.

[4] Sahibudin, Sharifi, M. \& Ayat, M, 2008.

Combining ITIL, COBIT and ISO/IEC 27002 in Order to Design a Comprehensive IT Framework in Organizations. 2008 Second Asia International Conference on Modelling \& Simulation (AMS), pp.749-753. Available http://ieeexplore.ieee.org/lpdocs/epic0 3/wrapper.h tm?arnumber $=4530569$ [Accessed May 4, 2014]. 